\title{
Peculiar Piezoelectric Properties of Soft Two-Dimensional Materials
}

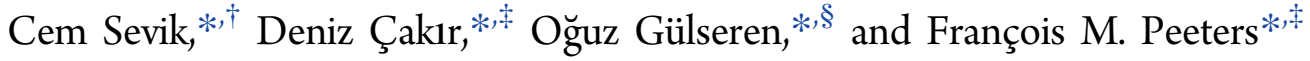 \\ ${ }^{\dagger}$ Department of Mechanical Engineering, Faculty of Engineering, Anadolu University, Eskisehir, TR 26555, Turkey \\ ${ }^{\ddagger}$ Department of Physics, University of Antwerp, Groenenborgerlaan 171, B-2020 Antwerpen, Belgium \\ ${ }^{\S}$ Department of Physics, Bilkent University, Bilkent, Ankara 06800, Turkey
}

ABSTRACT: Group II-VI semiconductor honeycomb monolayers have a noncentrosymmetric crystal structure and therefore are expected to be important for nano piezoelectric device applications. This motivated us to perform firstprinciples calculations based on density functional theory to unveil the piezoelectric properties (i.e., piezoelectric stress $\left(e_{11}\right)$ and piezoelectric strain $\left(d_{11}\right)$ coefficients) of these monolayer materials with chemical formula $\mathrm{MX}$ (where $\mathrm{M}=$ $\mathrm{Be}, \mathrm{Mg}, \mathrm{Ca}, \mathrm{Sr}, \mathrm{Ba}, \mathrm{Zr}, \mathrm{Cd}$ and $\mathrm{X}=\mathrm{S}, \mathrm{Se}, \mathrm{Te}$ ). We found that these two-dimensional materials have peculiar piezoelectric properties with $d_{11}$ coefficients 1 order of magnitude larger than those of commercially utilized bulk materials. A clear
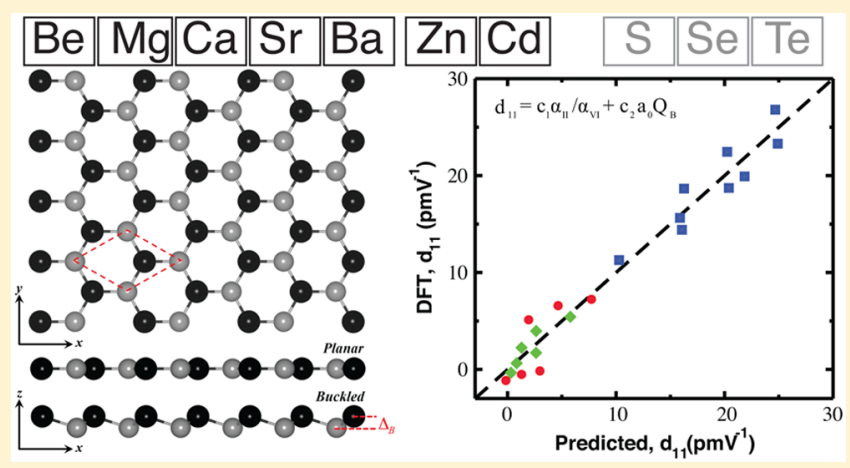
trend in their piezoelectric properties emerges, which originates mainly from their mechanical properties. We establish a simple correlation between the piezoelectric strain coefficients and the physical properties, as the natural elemental polarizabilities, the Bader charges, and lattice constants of the individual $\mathrm{M} / \mathrm{X}$ atoms and $\mathrm{MX}$ monolayers.

\section{INTRODUCTION}

Recent experimental and theoretical studies revealed that noncentrosymmetric two-dimensional (2D) materials exhibit high piezoelectric responses, which makes them very appealing for the next generation of sensors, actuators, transducers, and energy harvesters. Those applications are in the fields of nanorobotics, piezotronics, and nanoelectromechanical systems. $^{1-8}$ The piezoelectric properties of single layer $\mathrm{BN}, \mathrm{MoS}_{2}$, $\mathrm{MoSe}_{2}, \mathrm{MoTe}_{2}, \mathrm{WS}_{2}, \mathrm{WSe}_{2}$, and $\mathrm{WTe}_{2}$ were previously studied, ${ }^{9-12}$ and it was reported that the relaxed-ion piezoelectric stress $\left(e_{11}\right)$ and piezoelectric strain $\left(d_{11}\right)$ coefficients of these monolayers are comparable or even better than those of conventional bulk piezoelectric materials. Likewise, Zhuang et al. ${ }^{13}$ have shown that both the $e_{11}$ and $d_{11}$ coefficients of $\mathrm{CrS}_{2}$ are significantly larger than those of single layer $\mathrm{MoS}_{2}$. Subsequently, $\mathrm{Wu}$ et al. ${ }^{1}$ reported experimental evidence of piezoelectricity in free-standing monolayer $\mathrm{MoS}_{2}$ and they found that this material exhibits a strong piezoelectric effect for an odd number of layers in which case inversion symmetry is broken. Moreover, Zhu et al. ${ }^{2}$ measured the $e_{11}$ coefficient of this monolayer material and found $2.9 \times 10^{-10} \mathrm{C} \mathrm{m}^{-1}$, which is in good agreement with previous theoretical calculation. ${ }^{9}$

Following these studies, the piezoelectric properties of different noncentrosymetric $2 \mathrm{D}$ monolayer materials such as transition metal dichalcogenides (TMDCs) and oxides, ${ }^{14,15}$ group III monochalcogenides, ${ }^{16}$ and group IV monochalcogenides, ${ }^{3,17}$ were studied by first-principles calculations. Rather surprisingly, the relaxed-ion $d_{11}$ coefficient, which is a measure of the mechanical-electrical energy conversion ratio, of some of these materials was predicted to be 1 or 2 orders of magnitude larger than that of traditionally used bulk materials such as $\alpha$ quartz $^{18}\left(d_{11}=2.3 \mathrm{pm} \mathrm{V}^{-1}\right)$, wurtzite-GaN ${ }^{19}\left(d_{33}=3.1 \mathrm{pm}\right.$ $\left.\mathrm{V}^{-1}\right)$, and wurtzite-AlN ${ }^{19}\left(d_{33}=5.1 \mathrm{pm} \mathrm{V}^{-1}\right)$. For instance, values as high as $8.47,16.3,21.7,212.1$, and $250.5 \mathrm{pm} \mathrm{V}^{-1}$ have been obtained for monolayer $\mathrm{CrSe}_{2}, \mathrm{CrTe}_{2},{ }^{14} \mathrm{CdO},{ }^{15} \mathrm{GeSe}$, and $\mathrm{SnSe}^{3}$ crystals, respectively. These results clearly show the remarkably high piezoelectric properties of monolayer materials and their potential use for nanoscale technological applications.

Recently, Zheng et al. ${ }^{20}$ explored the structural stability of two-dimensional II-VI honeycomb structures using firstprinciples lattice-vibration frequency analysis and reported that graphene-like monolayers of $\mathrm{BeO}, \mathrm{MgO}, \mathrm{CaO}, \mathrm{ZnO}, \mathrm{CdO}$, $\mathrm{CaS}, \mathrm{SrS}, \mathrm{SrSe}, \mathrm{BaTe}$, and $\mathrm{HgTe}$ are dynamically stable. In addition, they confirmed the intrinsic semiconductor nature of these materials by hybrid functional calculations. These results motivated us to perform a systematic first-principles study to investigate piezoelectric and mechanical properties of these noncentrosymmetric single layer materials with chemical formula $\mathrm{MX}$, where $\mathrm{M}=\mathrm{Be}, \mathrm{Mg}, \mathrm{Ca}, \mathrm{Sr}, \mathrm{Ba}, \mathrm{Zn}, \mathrm{Cd}$ and $\mathrm{X}=$ $S$, Se, Te. Lattice parameters, elastic stiffness constants $\left(C_{11}\right.$ and $\left.C_{12}\right)$, Young modulus $(Y)$, piezoelectric stress coefficients $\left(e_{11}\right)$ and piezoelectric strain coefficients $\left(d_{11}\right)$ are calculated.

The present paper is organized as follows. We first present our computational methodology. Then, we calculated the elastic constants and piezoelectric properties. Lastly, we conclude with an overview of our main results.

Received: April 7, 2016

Revised: June 3, 2016

Published: June 9, 2016 


\section{METHOD}

Within the scope of the current study, first-principles calculations based on density functional-theory (DFT), as implemented in the Vienna $\mathrm{Ab}$ initio Simulation package (VASP) code, $^{21,22}$ are performed. The exchange-correlation interactions are treated using the generalized gradient approximation (GGA) within the Perdew-Burke-Ernzerhof (PBE) formulation. ${ }^{23,24}$ The single electron wave functions are expanded in plane waves with kinetic energy cutoff of $600 \mathrm{eV}$. For the structure optimizations, the Brillouin-zone integrations are performed using a $\Gamma$-centered regular $26 \times 26 \times 1 k$-point mesh within the Monkhorst-Pack scheme. ${ }^{25}$ The convergence criterion for electronic and ionic relaxations are set as $10^{-7}$ and $10^{-3} \mathrm{eV} / \AA$, respectively. To minimize the periodic interaction along the $z$-direction, the vacuum space between the layers is taken at least $15 \AA$. The coefficients of elastic stiffness tensor and piezoelectric tensor, $e_{i j k}$ are obtained by using densityfunctional perturbation theory (DFPT) ${ }^{26}$ as implemented in the VASP code. Here, a highly dense $k$-point mesh, $36 \times 36 \times$ 1 , is used to accurately predict these tensor components. The clamped-ion elastic and piezoelectric coefficients are obtained from the purely electronic contribution and the relaxed-ion coefficients are obtained from the sum of ionic and electronic contributions.

The number of independent piezoelectric tensor coefficient is deduced from the symmetry of the crystal. Due to the symmetry, we only have a non-vanishing piezoelectric effect along the armchair direction for planar structures. The piezoelectric constants are zero for the zigzag direction since this material family is centrosymmetric along the zigzag direction. Thus, the piezoelectric tensor of these hexagonal crystal systems, schematically shown in Figure 1 becomes:

$$
e_{i j}=\left(\begin{array}{ccc}
e_{11} & -e_{11} & 0 \\
0 & 0 & -\frac{e_{11}}{2} \\
e_{31} & e_{31} & 0
\end{array}\right)
$$

Here, we only need to calculate the $e_{11}$ component of the piezoelectric stress tensor. The piezoelectric coefficient $e_{31}$ is only relevant for a buckled monolayer. Because the calculated $e_{31}$ and $d_{31}$ coefficients are quite small, we are only interested in the in-plane piezoelectric properties. Following the $e_{11}$ calculations, the corresponding piezoelectric strain tensor $\left(d_{11}\right)$ of each material is predicted from the following relation as previously shown by Duerloo et al. ${ }^{9}$

$$
d_{11}=e_{11} /\left(C_{11}-C_{12}\right)
$$

\section{RESULTS}

It is essential that a piezoelectric material has to be an insulator or semiconductor with a sufficiently wide band gap to avoid current leakage. Zheng et $\mathrm{al}^{20}$ confirmed the intrinsic semiconductor nature of the materials considered in this study by hybrid functional calculations. They estimated indirect band gap values of $\mathrm{MX}$ with $\mathrm{M}=\mathrm{Be}, \mathrm{Mg}, \mathrm{Ca}, \mathrm{Sr}, \mathrm{Ba}$ and direct band gap values of $\mathrm{MX}$ with $\mathrm{M}=\mathrm{Zn}$ and $\mathrm{Cd}$ as large as $2 \mathrm{eV}$, which are sufficiently large for piezoelectric applications.

With the intention to investigate piezoelectric properties of these materials, we first optimize the geometries and calculate the relaxed- and clamped-ion elastic stiffness coefficients $\left(C_{11}\right.$ and $\left.C_{12}\right)$, Young's moduli $\left(Y=\left(C_{11}^{2}-C_{12}^{2}\right) / C_{11}\right)$, and Poisson

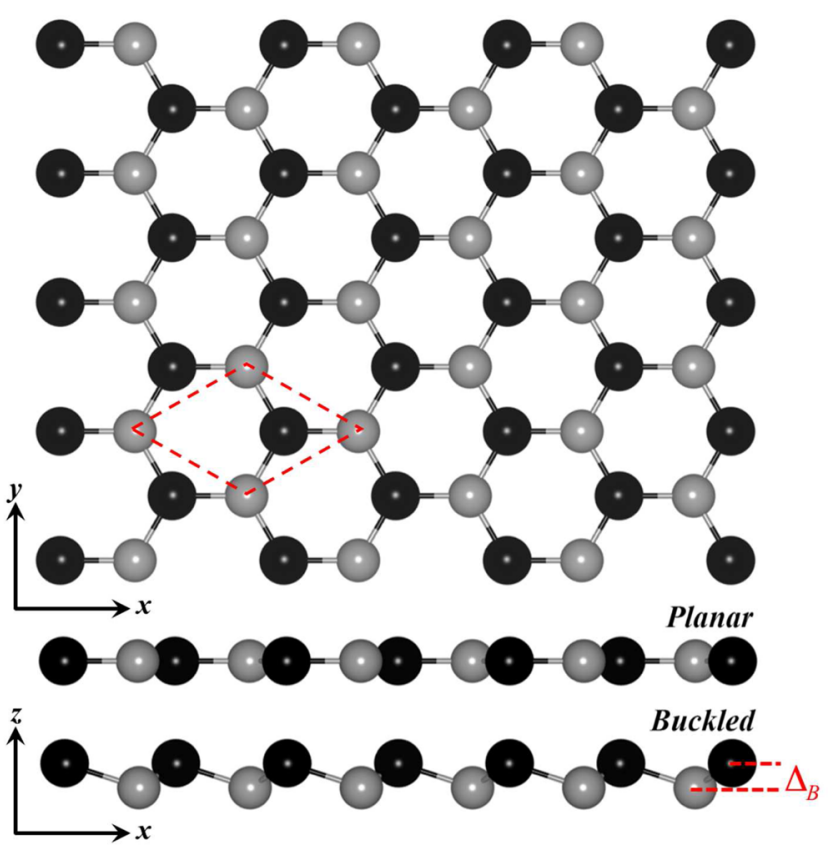

Figure 1. Top and side views of graphene-like honeycomb structure for group II-VI MX monolayers, where $\mathrm{M}=\mathrm{Be}, \mathrm{Mg}, \mathrm{Ca}, \mathrm{Sr}, \mathrm{Ba}, \mathrm{Zr}$, $\mathrm{Cd}$ and $\mathrm{X}=\mathrm{S}, \mathrm{Se}, \mathrm{Te} . \Delta_{\mathrm{B}}$ is the buckling parameter for the nonplanar monolayers.

ratios $\left(\nu=C_{12} / C_{11}\right)$ of all the materials, as depicted in Table 1 . Because local density approximation was used in ref 20, we obtain slightly larger equilibrium lattice constants. The calculated buckling parameters, $\Delta_{\mathrm{B}}$ (Figure 1), for nonplanar structures are $0.21,0.41,0.32$, and $0.49 \AA$ for $\mathrm{ZnSe}, \mathrm{ZnTe}$, $\mathrm{CdSe}$, and $\mathrm{CdTe}$, respectively. The first observation from Table 1 is that $C_{11}, C_{12}, Y$, and $\nu$ of group II-VI materials decreases with an increase in the row number of the group II element. In addition, for each group II element, the MX monolayer becomes stiffer with an increase in the row number of the group VI element. Note that the relaxed-ion elastic constants, i.e., $C_{11}$ and $C_{12}$, are mostly smaller than the clamped-ion ones because the internal relaxation of the ions allows the release of some of the stress in the former, Table 1 . All the materials considered in this study are found to be less stiff when compared to graphene $(Y=341 \mathrm{~N} / \mathrm{m}){ }^{27}$ single layer $h$-BN $(Y$ $=275.9 \mathrm{~N} / \mathrm{m}),{ }^{27}$ and most of the TMDCs, ${ }^{14}$ and the Poisson ratios, $\nu$, of most of the MX compounds are much larger than that of TMDCs. ${ }^{27}$ On the contrary, it should be noticed that the calculated elastic constants are positive and satisfy the Born stability criteria for crystals having hexagonal symmetry (for which the following conditions must be met for mechanically stable hexagonal crystals: $C_{11}>\left|C_{12}\right|$ and $\left.C_{11}>0\right) .^{28,29}$

Figure 2 shows the results for clamped-ion (purely electronic) and relaxed-ion (electronic plus ionic) $e_{11}$ and $d_{11}$ coefficients of $\mathrm{MX}$ structures with $\mathrm{M}=\mathrm{Be}, \mathrm{Mg}, \mathrm{Ca}, \mathrm{Sr}, \mathrm{Ba}$ and $\mathrm{X}=\mathrm{S}$, Se, Te. The calculated values clearly show that the electronic and ionic polarization of these materials have opposite sign and the magnitude of the ionic contribution is larger than the electronic contribution for all the considered materials except those with $\mathrm{Be}$ atom.

The contribution of the internal relaxation to the relaxed-ion $e_{11}$ coefficients decreases when moving downward in the group of chalcogenide atoms. Owing to their larger in-plane lattice parameters, the MX compounds with larger $\mathrm{M}$ and $\mathrm{X}$ atoms undergo a smaller internal relaxation, which reduces the ionic 
Table 1. Calculated Equilibrium Lattice Constants $a_{0}(\AA)$, Net Bader Charge $Q$ on the Metal Atoms $\left(e^{-}\right)$, Electronegativity Difference $\left(\Delta \chi=\chi_{\mathrm{X}}-\chi_{\mathrm{M}}\right)$ of $\mathrm{M}$ and $\mathrm{X}$ Atoms (in Pauling Scale), Clamped- and Relaxed-Ion Elastic Constants $C_{11}$ and $C_{12}(\mathrm{~N} /$ $\mathrm{m})$, the Young Modulus $Y(\mathrm{~N} / \mathrm{m})$, and the Poisson Ratios $\nu\left(=C_{12} / C_{11}\right)$

\begin{tabular}{|c|c|c|c|c|c|c|c|c|c|c|c|}
\hline \multirow[b]{2}{*}{ material } & \multirow[b]{2}{*}{$a_{0}$} & \multirow[b]{2}{*}{$Q$} & \multirow[b]{2}{*}{$\Delta \chi$} & \multicolumn{4}{|c|}{ clamped } & \multicolumn{4}{|c|}{ relaxed } \\
\hline & & & & $C_{11}$ & $C_{12}$ & $\mathrm{Y}$ & $\nu$ & $C_{11}$ & $C_{12}$ & $\mathrm{Y}$ & $\nu$ \\
\hline $\mathrm{BeS}$ & 3.456 & 1.59 & 1.01 & 87 & 22 & 81 & 0.25 & 78 & 31 & 65 & 0.40 \\
\hline $\mathrm{BeSe}$ & 3.671 & 1.55 & 0.98 & 75 & 19 & 70 & 0.25 & 67 & 26 & 57 & 0.39 \\
\hline $\mathrm{BeTe}$ & 4.033 & 1.45 & 0.53 & 61 & 14 & 57 & 0.23 & 54 & 21 & 46 & 0.39 \\
\hline $\mathrm{MgS}$ & 4.095 & 1.68 & 1.27 & 56 & 18 & 49 & 0.32 & 45 & 29 & 26 & 0.64 \\
\hline $\mathrm{MgSe}$ & 4.308 & 1.60 & 1.24 & 48 & 16 & 42 & 0.33 & 39 & 25 & 23 & 0.64 \\
\hline $\mathrm{MgTe}$ & 4.684 & 1.54 & 0.79 & 38 & 13 & 34 & 0.34 & 31 & 20 & 19 & 0.65 \\
\hline $\mathrm{CaS}$ & 4.572 & 1.45 & 1.58 & 39 & 18 & 32 & 0.46 & 32 & 25 & 12 & 0.78 \\
\hline $\mathrm{CaSe}$ & 4.780 & 1.44 & 1.55 & 35 & 15 & 28 & 0.43 & 27 & 22 & 9 & 0.81 \\
\hline $\mathrm{CaTe}$ & 5.160 & 1.43 & 1.10 & 29 & 12 & 23 & 0.41 & 22 & 19 & 7 & 0.86 \\
\hline $\mathrm{SrS}$ & 4.849 & 1.50 & 1.63 & 35 & 16 & 28 & 0.46 & 28 & 23 & 10 & 0.82 \\
\hline $\mathrm{SrSe}$ & 5.058 & 1.48 & 1.60 & 31 & 14 & 25 & 0.45 & 24 & 20 & 8 & 0.83 \\
\hline SrTe & 5.438 & 1.43 & 1.15 & 26 & 11 & 21 & 0.42 & 20 & 17 & 6 & 0.85 \\
\hline $\mathrm{BaS}$ & 5.140 & 1.42 & 1.69 & 30 & 16 & 22 & 0.53 & 25 & 21 & 8 & 0.84 \\
\hline $\mathrm{BaSe}$ & 5.350 & 1.39 & 1.66 & 27 & 14 & 20 & 0.52 & 22 & 18 & 7 & 0.82 \\
\hline $\mathrm{BaTe}$ & 5.728 & 1.36 & 1.21 & 23 & 11 & 17 & 0.48 & 18 & 16 & 5 & 0.89 \\
\hline $\mathrm{ZnS}$ & 3.892 & 0.95 & 0.93 & 70 & 19 & 64 & 0.27 & 59 & 30 & 44 & 0.51 \\
\hline $\mathrm{ZnSe}$ & 4.097 & 0.74 & 0.90 & 58 & 16 & 54 & 0.28 & 40 & 15 & 34 & 0.38 \\
\hline $\mathrm{ZnTe}$ & 4.404 & 0.50 & 0.45 & 47 & 13 & 43 & 0.28 & 34 & 13 & 29 & 0.38 \\
\hline $\mathrm{CdS}$ & 4.258 & 0.90 & 0.89 & 56 & 18 & 50 & 0.32 & 46 & 28 & 28 & 0.61 \\
\hline $\mathrm{CdSe}$ & 4.440 & 0.73 & 0.86 & 47 & 15 & 42 & 0.32 & 30 & 15 & 23 & 0.50 \\
\hline $\mathrm{CdTe}$ & 4.723 & 0.52 & 0.41 & 39 & 12 & 35 & 0.31 & 25 & 11 & 20 & 0.44 \\
\hline
\end{tabular}
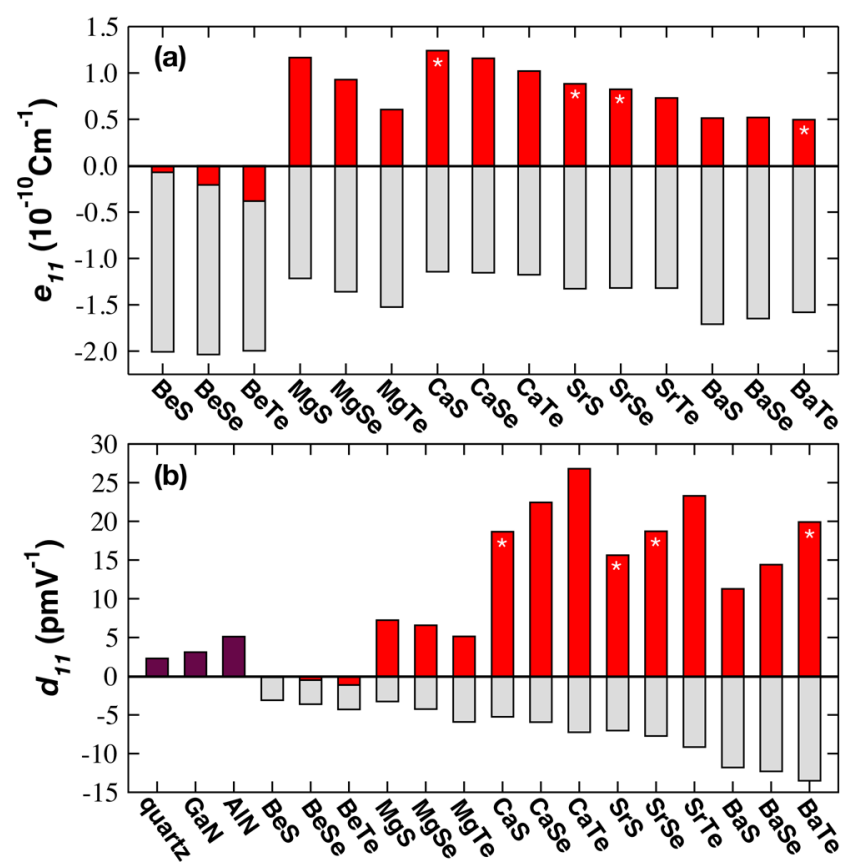

Figure 2. Calculated clamped- and relaxed-ion (a) piezoelectric stress $\left(e_{11}\right)$ and $(\mathrm{b})$ piezoelectric strain $\left(d_{11}\right)$ coefficients for MX monolayers (where $\mathrm{M}=\mathrm{Be}, \mathrm{Mg}, \mathrm{Ca}, \mathrm{Sr}$, and $\mathrm{Ba}$ ). Red (gray) bars depict the relaxed-ion (clamped-ion) piezoelectric coefficients. For comparison, $d_{11}$ coefficient of $\alpha$-quartz, GaN, and AlN are also depicted in (b). The white asterisk indicates that it is a dynamically stable material.

contribution. This may be due to the fact that MX compounds possessing large cell parameters have a very smooth potential energy surface. Thus, moving slightly away from the equilibrium structure does not change the total energy of the system. Although the clamped-ion $e_{11}$ coefficients in the Ba- based compounds are larger than that in most of the group II elements, the relaxed-ion $e_{11}$ coefficients exhibit a opposite behavior.

Among MX materials, $\mathrm{MgS}, \mathrm{CaS}$, and $\mathrm{CaSe}$ have the highest and $\mathrm{BeS}$ has the smallest relaxed-ion $e_{11}$ coefficients, as seen in Figure 2a. Moreover, the predicted highest $e_{11}$ coefficient is smaller than the one calculated for $\mathrm{WS}_{2}\left(3.76,{ }^{14} 2.47,{ }^{9}\right.$ and $\left.2.12^{15}\right)$, which has the smallest relaxed-ion coefficient among the $\mathrm{Cr}$, Mo, and $\mathrm{W}$ based transition metal dichalcogenides (TMDCs). However, the picture is completely different when we consider the relaxed-ion $d_{11}$ coefficient, which is a measure of the mechanical-electrical energy conversion ratio, Figure $2 \mathrm{~b}$. In particular, the ones calculated for $\mathrm{MX}$ with $\mathrm{M}=\mathrm{Ca}, \mathrm{Sr}$, and $\mathrm{Ba}$ are notably larger than the values predicted for TMDCs, ${ }^{9,14,15}$ most of the monolayer materials such as $\mathrm{BN}$, GaSe, GaAs, and AlSb, ${ }^{3,20}$ and the bulk materials including $\alpha$ quartz, wurtzite-GaN, and wurtzite-AlN, ${ }^{18,19}$ which are widely used in industry. Furthermore, the materials previously reported as having good dynamic stability, namely, CaS, SrS, $\mathrm{SrSe}$, and $\mathrm{BaTe}{ }^{20}$ have appreciable $d_{11}$ coefficients with values of $18.66,15.64,18.73$, and $19.92 \mathrm{pm} \mathrm{V}^{-1}$, respectively.

As clearly understood from eq 2 , such a remarkable $d_{11}$ coefficient is obviously correlated to the mechanical properties of the structures because these materials possess quite similar $e_{11}$ coefficients; see elastic stiffness coefficients and Young's moduli listed in Table 1 . This explicitly indicates that, in this material class, the remarkable piezoelectric potential originates mainly from their mechanical responses. Although the relaxedion $e_{11}$ coefficients of MX materials span a limited range (0.07$1.24 \mathrm{pC} / \mathrm{m})$, the absolute values of the relaxed-ion $d_{11}$ coefficient vary over a much larger range of $0.15-27 \mathrm{pm} / \mathrm{V}$.

Though the relaxed-ion $e_{11}$ coefficient decreases when going from $S$ to $\mathrm{Te}$ for all group II elements, the relaxed-ion $d_{11}$ coefficient follows a different trend such that it increases when moving downward in the group of chalcogenides for the $\mathrm{Ca}, \mathrm{Sr}$ 
and $\mathrm{Ba}$ atoms. $\mathrm{BeX}$ and $\mathrm{MgX}$ compounds have relatively large electronegativity difference, which is expected to result in large relaxed-ion $d_{11}$ coefficients. However, due to their larger stiffness, the relaxed-ion $d_{11}$ coefficients of the $\mathrm{BeX}$ and $\mathrm{MgX}$ compounds are found to be significantly smaller than that of $\mathrm{MX}$ with $\mathrm{M}=\mathrm{Ca}, \mathrm{Sr}$, and $\mathrm{Ba}$ but are comparable with those of commercial piezoelectric materials, Figure $2 \mathrm{~b}$. Here it should be mentioned that, among TMDCs with $\mathrm{M}=\mathrm{Cr}$, Mo, and $\mathrm{W}$, $\mathrm{CrTe}_{2}$ has the largest $d_{11}$ coefficient whereas BeTe has one of the smallest $d_{11}$ coefficient among MX materials considered in this work.

In addition to $\mathrm{Be}, \mathrm{Mg}, \mathrm{Ca}, \mathrm{Sr}$, and $\mathrm{Ba}$ we also considered $\mathrm{Zn}$ and $\mathrm{Cd}$ based structures as well. Figure 3 shows the calculated
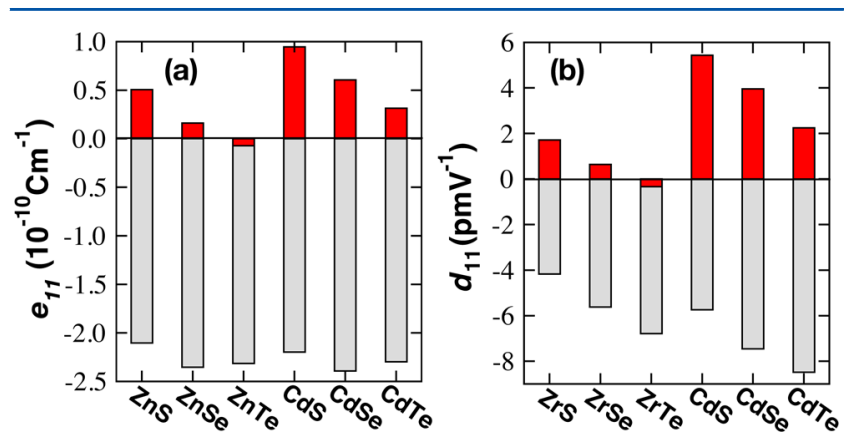

Figure 3. Calculated clamped- and relaxed-ion (a) piezoelectric stress $\left(e_{11}\right)$ and (b) piezoelectric strain $\left(d_{11}\right)$ coefficients for the MX monolayers (where $\mathrm{M}=\mathrm{Zr}$ and $\mathrm{Cd}$ ). Red (gray) bars depict the relaxed-ion (clamped-ion) piezoelectric coefficients.

$e_{11}$ and $d_{11}$ coefficients for $\mathrm{ZnX}$, and $\mathrm{CdX}$ with $\mathrm{X}=\mathrm{S}$, Se, and Te. The relaxed-ion $e_{11}$ coefficients of the MX materials (with $\mathrm{M}=\mathrm{Zn}$ and $\mathrm{Cd}$ ) fall into the range $0.07-0.94 \mathrm{pC} / \mathrm{m}$ and are comparable to those of the $\mathrm{MX}$ materials (with $\mathrm{M}=\mathrm{Be}, \mathrm{Mg}$, $\mathrm{Ca}, \mathrm{Sr}$, and $\mathrm{Ba}$ ) but much smaller than the $e_{11}$ coefficients of TMDCs. Furthermore, the clamped-ion $e_{11}$ coefficients are quite similar for the $\mathrm{ZnX}$ and $\mathrm{CdX}$ compounds. This means that the ionic contribution determines the trends found for the relaxed-ion $e_{11}$ coefficients, Figure 3a. Because the MX compounds are remarkably less stiff than the TMDCs, the predicted $d_{11}$ coefficients of MX materials are comparable with that of TMDCs. In contrast to $\mathrm{CaX}, \mathrm{SrX}$, and $\mathrm{BaX}$, the relaxedion $d_{11}$ coefficients of $\mathrm{ZnX}$ and $\mathrm{CdX}$ decrease when moving from $S$ to Te. Similar trends also hold for $\mathrm{MgX}$. In addition, $\mathrm{CdX}$ compounds have much larger $d_{11}$ coefficients with respect to $\mathrm{ZnX}$. Considering electronegativity differences between $\mathrm{Zn} /$ $\mathrm{Cd}$ and $\mathrm{X}$ atoms (which can be used to determine bond type in a material), the $\mathrm{ZnX} / \mathrm{CdX}$ compounds with $\mathrm{X}=\mathrm{Te}(\mathrm{S})$ belongs to a nonpolar covalent (polar covalent) bond class rather than a polar covalent (nonpolar covalent) bond class, which can be understood by comparing their Bader charges and electronegativity differences given in Table 1 . Thus, we can claim that the larger the electronegativity difference, the larger the $d_{11}$ coefficient is. If one compares elastic constants, $\mathrm{ZnX}$ and $\mathrm{CdX}$ compounds are stiffer than the group II monochalcogenides. According to eq 2 , the $d_{11}$ coefficient is inversely proportional to $\left(C_{11}-C_{12}\right)$, which is found to be large for $\mathrm{ZnX}$ and $\mathrm{CdX}$ materials. Even though $\mathrm{Te}$ is the most easily polarizable atom among the group VI elements, the relaxed-ion $d_{11}$ coefficients of $\mathrm{ZnTe}$ and CdTe are found to be one-third of those of $\mathrm{ZnS}$ and CdS.

Compared to TMDC properties, the piezoelectric properties of the MX materials are much more complicated. In the former, $d_{11}$ is only governed by the ratio of the natural elemental polarizabilities of metal and chalcogenide atoms such that the $d_{11}$ coefficient is maximized if we use a smaller metal atom and a larger chalcogenide atom. ${ }^{14}$ Finally, we attempt to relate the observed trends in the $d_{11}$ coefficients to some physical properties, such as atomic polarizabilities, Bader charges, lattice constants, etc., of individual atoms and their monolayers. We predict that the $d_{11}$ coefficient of the materials under study are directly proportional to the ratio of natural elemental polarizabilities of $\mathrm{M}$ and $\mathrm{X}$ atoms and the product of lattice constants and Bader charges, as shown in Figure 4. There is a

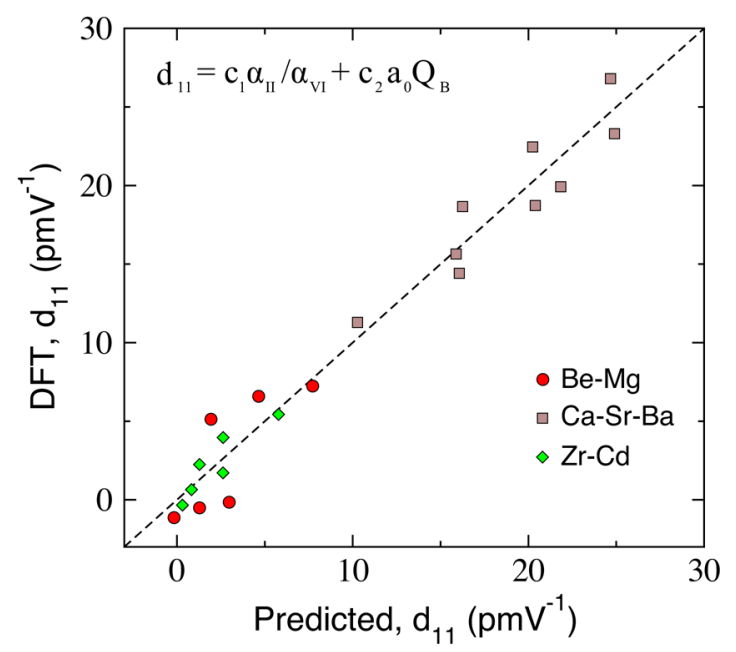

Figure 4. Correlation between the relaxed-ion $d_{11}$ coefficients of materials predicted by DFT calculations and the simple formula shown as inset. Here, $\alpha_{\mathrm{II}}$ and $\alpha_{\mathrm{VI}}$ represent the atomic polarizabilities ${ }^{30}$ of the group II and VI atoms and $c_{1}$ and $c_{2}$ are constants. The red filled circles, brown filled squares, and green filled diamonds denote the MX monolayers with $\mathrm{M}=\mathrm{Be}-\mathrm{Mg}, \mathrm{Ca}-\mathrm{Sr}-\mathrm{Ba}$, and $\mathrm{Zr}-\mathrm{Cd}$ groups, respectively.

very good correlation between the coefficients calculated with the simple formula, $d_{11}=c_{1} \frac{\alpha_{\mathrm{II}}}{\alpha_{\mathrm{VI}}}+c_{2} a_{0} Q_{B}$ and the DFPT calculations. ${ }^{15}$ Here, the natural elemental polarizabilities are borrowed from the experimental and calculated static dipole polarizabilities for the electronic ground states of neutral elements. ${ }^{30} a_{0}$ is the lattice constant and $Q_{\mathrm{B}}$ is the Bader charge given for the metal atoms (i.e., $\mathrm{Be}, \mathrm{Mg}, \mathrm{Ca}, \mathrm{Sr}, \mathrm{Ba}, \mathrm{Zr}, \mathrm{Cd}$ ) in Table 1. $c_{1}$ and $c_{2}$ are fitting constants shown in Table 2. In this

Table 2. Correlation Coefficients for the Simple Formula, $d_{11}=c_{1} \frac{\alpha_{\mathrm{II}}}{\alpha_{\mathrm{VI}}}+c_{2} a_{0} Q_{\mathrm{B}}$

\begin{tabular}{crr} 
materials $^{a}$ & \multicolumn{1}{c}{$c_{1}$} & \multicolumn{1}{c}{$c_{2}$} \\
$\mathrm{BeX}, \mathrm{MgX}$ & 3.2295 & -0.5501 \\
$\mathrm{CaX}, \mathrm{SrX}, \mathrm{BaX}$ & -1.4305 & 4.1700 \\
$\mathrm{ZnX}, \mathrm{CdX}$ & 9.6994 & -4.4837 \\
${ }^{a}$ Here, $\mathrm{X}$ represents $\mathrm{S}, \mathrm{Se}$, and Te atoms. &
\end{tabular}

equation, the second term is a kind of dipole moment scaled with a constant (i.e., $c_{2}$ ). Hence, it is possible to predict the piezoelectric constants without doing expensive calculations just by knowing tabulated atomic polarizabilities, the Bader charges (or electronegativities) and lattice parameters. Due to differences in mechanical properties of MX monolayers and electronic properties of individual $\mathrm{M}$ and $\mathrm{X}$ atoms, we identify 
three sets of fitting parameters that are exactly the same within the groups of $\mathrm{Be}-\mathrm{Mg}, \mathrm{Ca}-\mathrm{Sr}-\mathrm{Ba}$, and $\mathrm{Zn}-\mathrm{Cd}$. In each fitting group, $c_{1}$ and $c_{2}$ parameters have opposite signs. According to this simple formula, there is a correlation between the $d_{11}$ coefficient and the Bader charges. This simple expression also indicates that the $d_{11}$ coefficient is maximized if one considers a smaller metal atom and a larger chalcogenide atom as we show for $\mathrm{Ca}, \mathrm{Sr}$, and $\mathrm{Be}$.

\section{CONCLUSION}

We presented a detailed theoretical investigation of the piezoelectric properties of semiconducting two-dimensional $\mathrm{MX}$ (where $\mathrm{M}=\mathrm{Be}, \mathrm{Mg}, \mathrm{Ca}, \mathrm{Sr}, \mathrm{Ba}, \mathrm{Zr}, \mathrm{Cd}$ and $\mathrm{X}=\mathrm{S}$, Se, Te) monolayers. These structures are found to be strong candidates for future atomically thin piezoelectric applications. Due to their mechanical softness, MX monolayers have a surprisingly very high relaxed-ion $d_{11}$ coefficient. We showed that most of these materials have much better piezoelectric properties than most of the other two-dimensional materials and the wellknown conventional bulk piezoelectric materials. Notable MX monolayers with good stability and high relaxed-ion $d_{11}$ coefficient include BaTe $(19.92 \mathrm{pm} / \mathrm{V})$, SrSe $(18.73 \mathrm{pm} / \mathrm{V})$, $\mathrm{SrS}(15.64 \mathrm{pm} / \mathrm{V})$, and $\mathrm{CaS}(18.66 \mathrm{pm} / \mathrm{V})$. In addition, we noticed that it is possible to relate the calculated relaxed-ion $d_{11}$ coefficients with atomic polarizabilities and the Bader charges of $\mathrm{M}$ and $\mathrm{X}$ atoms, and the structural properties of $\mathrm{MX}$ monolayers. The calculated relaxed-ion $d_{11}$ coefficients can be fitted to a linear combination of two terms, the ratio of the $M$ and $\mathrm{X}$ polarizabilities and the product of the Bader charges and in-plane lattice constants.

\section{AUTHOR INFORMATION}

\section{Corresponding Authors}

*C. Sevik. E-mail: csevik@anadolu.edu.tr. Phone: +9 (0)532 1673208.

*D. Çakır. E-mail: deniz.cakir@uantwerpen.be.

*O. Gülseren. E-mail: gulseren@fen.bilkent.edu.tr.

*F. Peeters. E-mail: francois.peeters@uantwerpen.be.

Notes

The authors declare no competing financial interest.

\section{ACKNOWLEDGMENTS}

This work was supported by the Flemish Science Foundation (FWO-V1), the Methusalem foundation of the Flemish government and the Bilateral program FWO-TUBITAK between Flanders and Turkey. We acknowledge the support from the Scientific and Technological Research Council of Turkey (TUBITAK-115F024). Computational resources were provided by TUBITAK ULAKBIM, High Performance and Grid Computing Center (TR-Grid e-Infrastructure), and HPC infrastructure of the University of Antwerp (Cal-cUA) a division of the Flemish Supercomputer Center (VSC), which is funded by the Hercules foundation. C.S. acknowledges the support from the Scientific and Technological Research Council of Turkey (TUBITAK-113F333) and the support from Anadolu University (BAP-1407F335, -1505F200), and the Turkish Academy of Sciences (TUBA-GEBIP).

\section{REFERENCES}

(1) Wu, W.; Wang, L.; Li, Y.; Zhang, F.; Lin, L.; Niu, S.; Chenet, D.; Zhang, X.; Hao, Y.; Heinz, T. F.; et al. Piezoelectricity of Single-
Atomic-Layer $\mathrm{MoS}_{2}$ for Energy Conversion and Piezotronics. Nature 2014, 514, 470-474.

(2) Zhu, H.; Wang, Y.; Xiao, J.; Liu, M.; Xiong, S.; Wong, Z. J.; Ye, Z.; Ye, Y.; Yin, X.; Zhang, X. Observation of Piezoelectricity in FreeStanding Monolayer $\mathrm{MoS}_{2}$. Nat. Nanotechnol. 2015, 10, 151-155.

(3) Fei, R.; Li, W.; Li, J.; Yang, L. Giant Piezoelectricity of Monolayer Group IV Monochalcogenides: SnSe, SnS, GeSe, and GeS. Appl. Phys. Lett. 2015, 107, 173104-173108.

(4) Ong, M. T.; Reed, E. J. Engineered Piezoelectricity in Graphene. ACS Nano 2012, 6, 1387-1394.

(5) Kaul, A. B.; Wong, E. W.; Epp, L.; Hunt, B. D. Electromechanical Carbon Nanotube Switches for High-Frequency Applications. Nano Lett. 2006, 6, 942-947.

(6) Zhang, C.; Chen, W.; Zhang, C. Two-dimensional Theory of Piezoelectric Plates Considering Surface Effect. Eur. J. Mech. A-Solid 2013, 41, 50-57.

(7) Kim, K.-H.; Kumar, B.; Lee, K. Y.; Park, H.-K.; Lee, J.-H.; Lee, H. H.; Jun, H.; Lee, D.; Kim, S.-W. Piezoelectric two-dimensional nanosheets/anionic layer heterojunction for efficient direct current power generation. Sci. Rep. 2013, 3, 2017 EP.

(8) Lanza, M.; Reguant, M.; Zou, G.; Lv, P.; Li, H.; Chin, R.; Liang, H.; Yu, D.; Zhang, Y.; Liu, Z.; et al. High-Performance Piezoelectric Nanogenerators Using Two-Dimensional Flexible Top Electrodes. Adv. Mater. Interfaces 2014, 1, 1300101.

(9) Duerloo, K. A. N.; Ong, M. T.; Reed, E. J. Intrinsic Piezoelectricity in Two-Dimensional Materials. J. Phys. Chem. Lett. 2012, 3, 2871-2876.

(10) Michel, K. H.; Verberck, B. Theory of Elastic and Piezoelectric Effects in Two-Dimensional Hexagonal Boron Nitride. Phys. Rev. B: Condens. Matter Mater. Phys. 2009, 80, 224301.

(11) Michel, K. H.; Verberck, B. Phonon Dispersions and Piezoelectricity in Bulk and Multilayers of Hexagonal Boron Nitride. Phys. Rev. B: Condens. Matter Mater. Phys. 2011, 83, 115328.

(12) Michel, K. H.; Verberck, B. Theory of Phonon Dispersions and Piezoelectricity in Multilayers of Hexagonal Boron-Nitride. Phys. Status Solidi B 2011, 248, 2720.

(13) Zhuang, H. L.; Johannes, M. D.; Blonsky, M. N.; Hennig, R. G. Computational Prediction and Characterization of Single-Layer $\mathrm{CrS}_{2}$. Appl. Phys. Lett. 2014, 104, 022116-022119.

(14) Alyörük, M. M.; Aierken, Y.; Çakır, D.; Peeters, F. M.; Sevik, C. Promising Piezoelectric Performance of Single Layer Transition-Metal Dichalcogenides and Dioxides. J. Phys. Chem. C 2015, 119, 2323123237.

(15) Blonsky, M. N.; Zhuang, H. L.; Singh, A. K.; Hennig, R. G. Ab Initio Prediction of Piezoelectricity in Two-Dimensional Materials. ACS Nano 2015, 9, 9885-9891.

(16) Li, W.; Li, J. Piezoelectricity in Two-Dimensional Group-III Monochalcogenides. Nano Res. 2015, 8, 3796-3802.

(17) Gomes, L. C.; Carvalho, A.; Castro Neto, A. H. Enhanced Piezoelectricity and Modified Dielectric Screening of Two-Dimensional Group-IV Monochalcogenides. Phys. Rev. B: Condens. Matter Mater. Phys. 2015, 92, 214103.

(18) Behmann, R. Elastic and Piezoelectric Constants of alphaQuartz. Phys. Rev. 1958, 110, 1060-1061.

(19) Lueng, C. M.; Chan, H. L. W.; Surya, C.; Choy, C. L. Piezoelectric Coefficient of Aluminum Nitride and Gallium Nitride. J. Appl. Phys. 2000, 88, 5360-5363.

(20) Zheng, H.; Li, X.-B.; Chen, N.-K.; Xie, S.-Y.; Tian, W. Q.; Chen, Y.; Xia, H.; Zhang, S. B.; Sun, H.-B. Monolayer II-VI Semiconductors: A First-Principles Prediction. Phys. Rev. B: Condens. Matter Mater. Phys. 2015, 92, 115307.

(21) Kresse, G.; Hafner, J. Ab Initio Molecular Dynamics for Liquid Metals. Phys. Rev. B: Condens. Matter Mater. Phys. 1993, 47, 558-561.

(22) Wu, X.; Vanderbilt, D.; Hamann, D. R. Systematic Treatment of Displacements, Strains, And Electric Fields in Density-Functional Perturbation Theory. Phys. Rev. B: Condens. Matter Mater. Phys. 2005, 72, 035105 .

(23) Perdew, J. P.; Burke, K.; Ernzerhof, M. Generalized Gradient Approximation Made Simple. Phys. Rev. Lett. 1996, 77, 3865-3868. 
(24) Perdew, J. P.; Burke, K.; Ernzerhof, M. Generalized Gradient Approximation Made Simple. Phys. Rev. Lett. 1996, 77, 3865-3868.

(25) Monkhorst, H. J.; Pack, J. D. Special Points for Brillouin-Zone Integrations. Phys. Rev. B 1976, 13, 5188-5192.

(26) Nunes, R. W.; Gonze, X. Berry-Phase Treatment of the Homogeneous Electric Field Perturbation in Insulators. Phys. Rev. B: Condens. Matter Mater. Phys. 2001, 63, 155107.

(27) Çakır, D.; Peeters, F. M.; Sevik, C. Mechanical and Thermal Properties of $h$ - $\mathrm{MX}_{2}$ Monolayers a Comparative Study. Appl. Phys. Lett. 2014, 104, 203110-203113.

(28) Born, M.; Huang, K. Dynamical Theory of Crystal Lattices; Oxford University Press: Oxford, U.K., 1988.

(29) Nye, J. F. Physical Properties of Crystals, Their Representation by Tensors and Matrices; Clarendon Press: Oxford, U.K., 1957.

(30) Schwerdtfeger, P. Table of Experimental and Calculated Static Dipole Polarizabilities for the Electronic Ground States of the Neutral Elements (in Atomic Units): http://ctcp.massey.ac.nz/Tablepol2015. pdf. 2015, $\alpha_{\mathrm{Be}} / 37.71, \alpha_{\mathrm{Mg}} / 70.89, \alpha_{\mathrm{Ca}} / 155.90, \alpha_{\mathrm{Sr}} / 197.20, \alpha_{\mathrm{Ba}} / 275.68$, $\alpha_{\mathrm{Zn}} / 38.80, \alpha_{\mathrm{Cd}} / 46.60, \alpha_{\mathrm{S}} / 19.60, \alpha_{\mathrm{Se}} / 26.24, \alpha_{\mathrm{Te}} / 37.00$. 